ISSN 2236-0859

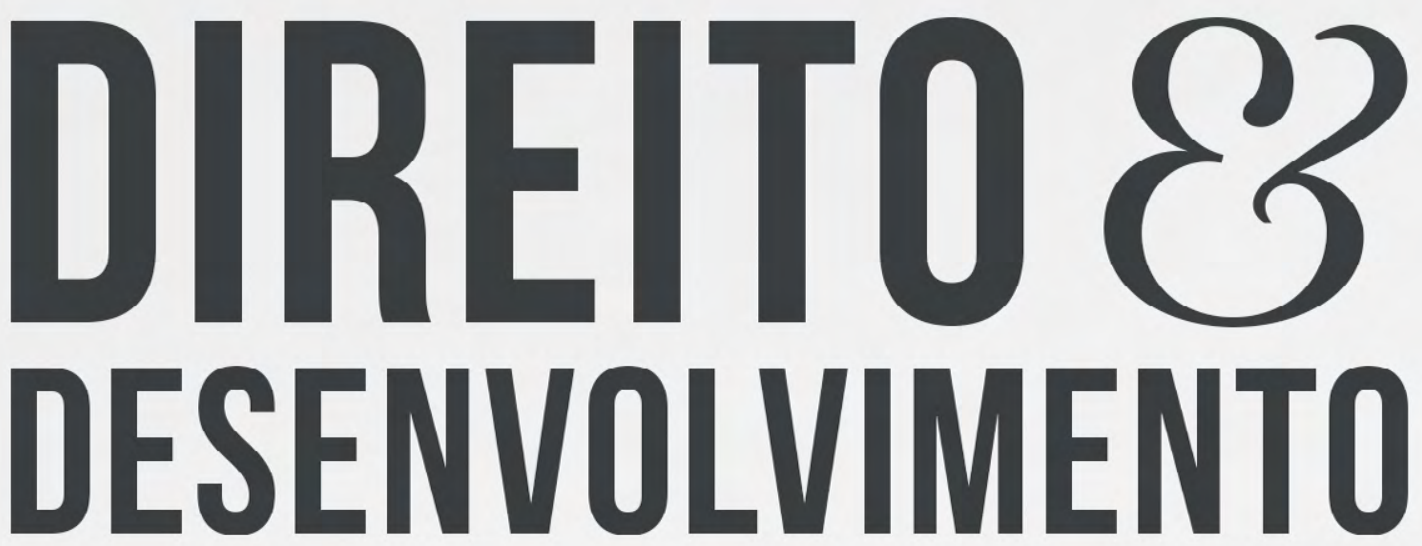

REVISTA DO PROGRAMA DE PÓS-GRADUAÇÃO EM DIREITO MESTRADO EM DIREITO E DESENVOLVIMENTO SUSTENTÁVEL

VIOLENCIA DE GÉNERO Y FUNCIÓN POLICIAL: ANÁLLISIS DE LA SITUACIÓN EN ESTADOS UNDDOS Y ESPAÑA

CATY VIDALES RODŔGUEZ

ANA T. CARAZO JOHANNNG 


\title{
VIOLENCIA DE GÉNERO Y FUNCIÓN POLICIAL: ANÁLISIS DE LA SITUACIÓN EN ESTADOS UNIDOS Y ESPAÑA
}

\author{
VIOLÊNCIA DE GÊNERO E FUNÇÃO POLICIAL: \\ ANÁLISE DA SITUAÇÃO NOS ESTADOS UNIDOS E NA ESPANHA
}

RESUMEN: La violencia contra mujeres y niñas se ha convertido en una auténtica pandemia y ha sido calificada como una auténtica violación de los derechos humanos. Ante la magnitud del problema, los legisladores nacionales no han permanecidos impasibles y, por esa misma razón, no debe extrañar la ingente cantidad de trabajos doctrinales que se dedican al tema. El presente artículo, sin embargo, aborda esta problemática desde un enfoque al que, hasta ahora, se le ha prestado escasa atención, cual es el papel que tiene asignado la policía y la eventual responsabilidad del Estado y se hace, además, desde una perspectiva comparada entre los ordenamientos norteamericano y español por considerarse un referente en política igualitarias.

Palabras-clave: Violencia de género. Función policial. Responsabilidad del Estado.

RESUMO: A violência contra mulheres e meninas tornou-se uma verdadeira pandemia e tem sido descrita como uma violação autêntica dos direitos humanos. Dada a magnitude do problema, os legisladores nacionais não permaneceram impassíveis e, por essa razão, não devem perder a enorme quantidade de trabalho doutrinário que é dedicado ao assunto. Este artigo, no entanto, aborda este problema a partir de uma abordagem para a qual, até o momento, pouca atenção tem sido dada, qual é o papel atribuído à polícia e a eventual responsabilidade do Estado, e também é feito de uma perspectiva comparada entre os sistemas jurídicos norte-americano e espanhol, porque eles são considerados uma referência na política igualitária.

Palavras-chave: Violência de genêro. Função policial. Responsabilidade do Estado

*Profesora Titular de Derecho Penal (Acreditada como Catedrática) Universitat Jaume I. E-mail: vidales@uji.es

** Vice directora del Center for the Administration of Justice. Florida International University. E-mail: ana.carazo-johanning@fiu.edu 


\section{INTRODUCCIÓN}

No creemos que admite discusión alguna que la violencia contra la mujer constituye una patente violación de los derechos humanos que alcanza, según la ONU, unas proporciones pandémicas³. A la vista del documento titulado "Hechos y cifras: acabar con la violencia contra mujeres y niñas" ${ }^{4}$, no parece una calificación exagerada atendiendo a las alarmantes cifras que se manejan. Así es por cuanto que se estima que el $35 \%$ de las mujeres de todo el mundo ha sufrido violencia física y/o sexual, pudiendo llegar, en algunos países hasta el 70 $\%$. Igual de preocupantes son los datos que se refieren a la violencia psíquica ya que sitúan en el $43 \%$ el índice de mujeres que la ha experimentado en los 28 países miembros de la Unión Europea ${ }^{6}$ aunque, en este caso, como reconoce el referido informe ${ }^{7}$, las dificultades de medición son aún mayores.

El hecho de que en todos estos casos el protagonista tenga o haya tenido una especial vinculación afectiva con la víctima hace todavía más execrable la comisión de estos delitos. Pero, por repudiables que pudieran ser, no son sin embargo, los únicos ataques de los que la mujer o niña, sólo por serlo, puede ser objeto. En efecto, a los homicidios/asesinatos, lesiones, agresiones sexuales, amenazas, coacciones, privaciones de libertad o malos tratos en el ámbito familiar, se le suman otros números no menos inquietantes: los más de 700 millones de mujeres que fueran obligadas a casarse con menos de 18 años de edad (1 de cada 3 antes de cumplir los 15 años) ${ }^{8}$, los 200 millones de niñas y mujeres que han sufrido algún tipo de mutilación/ablación genital ${ }^{9}$, que el $70 \%$ de las víctimas de trata de seres humanos lo sean mujeres o niñas ${ }^{10}$ o que 1 de cada 10 mujeres de la Unión Europea declare haber sido víctima de ciberacoso ${ }^{11}$. Finalmente, y pesar de que ante estas apabullantes cifras, tiene una importancia menor, no debe obviarse la discriminación más sutil, pero no menos frecuente, que se da en otros ámbitos, especialmente, en el laboral y que se incrementa cuando además de ser mujer, se pertenece a un colectivo especialmente vulnerable (inmigrante en situación irregular, discapacidad, enfermedad, orientación sexual, con riesgo de exclusión social, etc.).

La magnitud del problema y las devastadoras consecuencias para la vida, la libertad, la salud física y mental y los derechos reproductivos y sexuales de la mujer justifican la existencia de diferentes iniciativas supranacionales que pretenden poner fin a esta grave problemática. De cita obligada resulta la Declaración sobre la eliminación de la violencia contra la mujer que, incidiendo en la línea marcada por la Convención sobre la eliminación de todas las formas de discriminación contra la mujer, fue aprobada en 1993 por la Asamblea General de Naciones Unidas (Resolución 48/104). En el ámbito americano destaca la Convención Interamericana para prevenir, sancionar y erradicar la violencia contra la mujer o Convención de Belém do Pará, elaborada por la Organización de Estados Americanos, en 1994; y, finalmente, en el contexto europeo, se hace preciso mencionar el Convenio del Consejo de Europa para prevenir y combatir la violencia contra las mujeres, firmado en Estambul en 2011. Todos estos textos tienen en común reconocer que la violencia contra la mujer constituye una violación de los derechos humanos y las libertades fundamentales, que limita o cercena el ejercicio de esos derechos y libertades y, además, admiten que este tipo de violencia es una manifestación de relaciones de poder históricamente desiguales entre el hombre y la mujer que han conducido a la dominación de la mujer y a su discriminación lo que, sin duda, afecta a su dignidad.

3 http://www.unwomen.org/es/digital-library/multimedia/2015/11/infographic-violence-against-women

4 Fecha de actualización: febrero 2016; disponible en http://www.unwomen.org/es/what-we-do/ending-violence-against-women/ facts-and-figures

5 Datos extraídos del documento titulado "Hechos y cifras: acabar con la violencia contra las mujeres y niñas" (fecha de); disponible en http://www.unwomen.org/es/what-we-do/ending-violence-against-women/facts-and-figures

6 Datos extraídos de Violence against women: an EU-wide survey, Agencia Europea de Derechos Fundamentales, 2014), p. 71. Puede consultarse en http://fra.europa.eu/sites/default/files/fra-2014-vaw-survey-main-results-apr14_en.pdf

7 Op. y loc. cit.

8 "Hechos..., op. y loc. cit.

9 Female Genital Mutilation/Cutting: A global concern. Disponible en http://www.unwomen.org/es/what-we-do/ending-violenceagainst-women/facts-and-figures\#notes. UNICEF 2016, citado en "Hechos..., op. y loc. cit.

10 Global Report on Trafficking in persons. UNODC, 2014; p. 5 y 11, citado en "Hechos..., op. y loc. cit.

11 Violence against women: an EU-wide survey, Agencia Europea de Derechos Fundamentales, 2014, p. 104. citado en "Hechos..., op. y loc. cit. 
Como no podía ser de otra manera, tampoco los legisladores nacionales han permanecido impasibles ante esta realidad y, con el fin de proporcionar una tutela más efectiva a las víctimas de este tipo de violencia, han adoptado medidas que se caracterizan por un claro enfoque multidisciplinar. Un buen ejemplo de esta técnica legislativa es la Ley Contra la Violencia de las Mujeres (Violence Against Women Act), conocida como VAWA, que se promulgó en 1994 y es la primera ley federal aprobada sobre el tema ${ }^{12}$. La importancia de VAWA está fuera de toda duda atendiendo a que reconoció un nuevo derecho fundamental: "el derecho a vivir libre de la violencia generada en virtud de género", aunque se trató de una decisión polémica dudándose, incluso, de su constitucionalidad ${ }^{13}$. El enfoque integral con el que se pretendía hacer frente a esta problemática queda de manifiesto si se toma en consideración que, además de establecer sanciones ante la realización de estas conductas, instauró mecanismos para la protección y asistencia a las víctimas, como la creación de "hogares" o refugios" ${ }^{14}$. Tras las sucesivas reformas experimentadas por la Ley (2000, 2005 y 2013), se ha ido ampliando este tipo de iniciativas mediante la adopción de programas de asistencia legal a la víctima, programas de tratamiento y participación en los mismos para cónyuges o parejas abusadores como condición previa a la emisión de una orden de libertad condicional o probation, programas de prevención comunitaria, financiamiento de centros de crisis, establecimiento de programas de asistencia específicos atendiendo a la diversidad cultural o al idioma, la extensión de estas medidas a víctimas con estado migratorio indefinido o permanencia ilegal en el país o la inclusión de mujeres indígenas, lesbianas, gays, bisexuales o transexuales.

Merece también una mención especial el caso de España que, con la aprobación de la Ley Orgánica 1/2004, de 28 de diciembre, de Medidas de Protección Integral contra la Violencia de Género ${ }^{15}$, pasó a convertirse en un referente por cuanto que adopta medidas de discriminación positiva, incluso en materia penal lo que, evidentemente, fue objeto de una encendida discusión y, de hecho, se plantearon numerosas cuestiones de inconstitucionalidad que giraban en torno a la posible vulneración del principio de igualdad, al menoscabo de la dignidad de la mujer, a la afección del derecho a la presunción de inocencia y, por último, al principio de culpabilidad. El Tribunal Constitucional, en la sentencia 59/2008, de 14 de mayo, zanjó la cuestión. Los principales argumentos que condujeron a declarar la compatibilidad de la Ley con las exigencias constitucionales fueron que se trata de una igualdad valorativa, que la diferenciación jurídica que establece persigue un fin legítimo y, finalmente, que las consecuencias de esta discriminación no resultan desproporcionadas ${ }^{16}$.

En cualquier caso, interesa destacar que, en consonancia con su encabezamiento, persigue un tratamiento integral de la violencia de género adoptando medidas de sensibilización, prevención y

12 No así a nivel estatal, ya que la situación era diferente. Si bien es cierto que antes de 1977 ninguno de los Estados Unidos tenía una legislación que permitiera el arresto de personas en caso de violencia doméstica, a no ser que un oficial de policía fuera testigo de la agresión, la situación experimenta un notable cambio y ya en 1980 muchos Estados contaban con previsiones legislativas al respecto que incluían la emisión de órdenes de protección, autorización de arrestos sin orden previa y por ataques menores, etc. Para mayor información sobre el progreso y los avances de la legislación en materia de violencia doméstica, puede verse en HANNA, C., "No Right to Choose: Mandated Victim Participation in Domestic Violence Prosecution”, en 109 Harvard Law Revue 1849, 1857-62 (1996). 13 En efecto, se entendió que se habían excedido las facultades legislativas federales conforme a la Cláusula de Comercio. Los tribunales, sin embargo, indicaron que "la violencia doméstica genera un temor a la violencia motivada por prejuicios de género que resulta en una limitación a la participación en el trabajo, mercado laboral y consecuentemente afecta sustancialmente el comercio interestatal, así acreditado por el Congreso durante el proceso de promulgación del estatuto" (Doe v. Doe, United States District Court of Connecticut), posición que se mantuvo por varios años. Posteriormente, la Corte Suprema de Justicia en United States v. Morrison, [529 U.S. 598 (200o)], declaró que los delitos de violencia doméstica no son, por su naturaleza, económicos y por tanto rechazó la posición de que se pudiese estar frente a un derecho fundamental.

14 Al respecto, pude verse, 1996 U. Illinois. Law. Review. 533, 543. "passed the Violence Against Women Act as part of the Federal Crime Bill, which President Clinton signed into law in September 1994”. Véase también, William J. Clinton, Proclamation No. 6927 impreso en 40 Wkly. Compilation Presidential Documents 1960 (1996). Citados por ADLER, J. R., "Strengthening Victims' Rights In Domestic Violence Cases: An Argument For 30-Day Mandatory Restraining Orders In Massachusetts", en The Boston Public Interest Law Journal Winter, 1999, 8 B.U. Pub. Int. L.J. 303. en donde se referencian manifestaciones del entonces Presidente Clinton indicando que la intención de las normas que se promulgaron era de proveer a las autoridades con los medios necesarios para acusar y sancionar a los abusadores y promover que los Estados se unan en un esfuerzo común para implementar normas dentro de sus procesos de reforma social que proporcionen alternativas ante el problema de la violencia familiar.

15 El texto íntegro puede consultarse en https://www.boe.es/buscar/act.php?id=BOE-A-2004-21760

16 Sobre estos aspectos, puede verse, entre otros, FUENTES SORIANO, O., "La constitucionalidad de la Ley Orgánica de medidas de protección integral contra la violencia de género", en La Ley, nº 5, 2005; p. 1153 a 1170; VILLACAMPA ESTIARTE, C., "El maltrato singular cualificado por razón de género. Debate acerca de su constitucionalidad”, en Revista Electrónica de Derecho Penal y Criminología, 2007; disponible en criminet.ugr.es/recpc/o9/recpco9-12.pdf. 
detección, reconociendo expresamente los derechos que asisten a las mujeres víctimas de este tipo de violencia y estableciendo un sistema integral de tutela institucional que demuestra un serio compromiso en la erradicación de la misma. Estos esfuerzos no deben extrañar habida cuenta que, según puede leerse en las primeras frases de la Exposición de Motivos que justifica la existencia de la Ley, "la violencia de género no es un problema que afecte al ámbito privado. Al contrario, se manifiesta como el símbolo más brutal de la desigualdad existente en nuestra sociedad. Se trata de una violencia que se dirige sobre las mujeres por el hecho mismo de serlo, por ser consideradas, por sus agresores, carentes de los derechos mínimos de libertad, respeto y capacidad de decisión".

A pesar de la innegable importancia de ambos textos, no va a efectuarse en esta sede un análisis de las consecuencias derivadas de su implementación que, por otra parte, sería innecesario tomando en consideración el amplio número de trabajos que se le han dedicado ${ }^{17}$. Por el contrario, el objetivo, mucho más modesto, que se persigue es examinar un aspecto al que no se le ha prestado tanta atención. Nos referimos a la función policial en los casos de violencia de género. Es fácil explicar esta elección si se tiene en cuenta que la policía es el primer organismo que, dentro del control social formalizado, actúa teniendo encomendadas competencias en materia de prevención, investigación y control del cumplimiento de las decisiones judiciales. De este modo, además de asistir y proteger a la víctima, su actuación condiciona que el delito cometido sea efectivamente castigado. Por otro lado, debe tenerse en cuenta que la confianza en esta institución puede contribuir a que se reduzca la inquietante cifra negra que todavía existe en relación con esta manifestación de la delincuencia. No obstante, antes de abordar la tarea propuesta, se impone definir qué se entiende por violencia de género, cuestión esta de la que pasamos a ocuparnos.

\section{PRECISIONES TERMINOLÓGICAS}

En atención a lo que dispone el artículo 1 de la Declaración de Naciones Unidas sobre la eliminación de la violencia contra la mujer, es "todo acto de violencia basado en la pertenencia al sexo femenino que tenga o pueda tener como resultado un daño o sufrimiento físico, sexual o psicológico para las mujeres, inclusive las amenazas de tales actos, la coacción, la privación arbitraria de libertad, tanto si se produce en la vida pública o privada”, especificándose a continuación - artículo 2 -, aunque no de modo taxativo, qué actos merecen esta consideración. En parecidos términos se pronuncia la Convención Interamericana para prevenir, sancionar y erradicar la violencia contra la mujer que, en su primer artículo establece que debe entenderse "cualquier acción o conducta, basada en su género, que cause muerte, daño o sufrimiento físico, sexual o psicológico a la mujer, tanto en el ámbito público como en el privado".

Por su parte, el Convenio del Consejo de Europa para prevenir y combatir la violencia contra las mujeres introduce una significativa matización al distinguir entre violencia contra las mujeres y violencia

17 Por lo que a la legislación norteamericana se refiere, para mayor información sobre el progreso y los avances de la legislación en materia de violencia doméstica puede verse, entre otros, HANNA C., "No Right..., op. cit.; FAGAN, J., "The Criminalization of Domestic Violence: Promises and Limits", NIJ Research Report, 1996; POLLITZ WORDEN, A., "Violence Against Women: Synthesis of Research for Judges", diciembre 2002, NCJ 199911; POLICE FUNDATION, Richmond's Second Responders: Partnering with Police Against Domestic Violence, marzo 2005; GOLDSCHEID J., "Gender Violence and Work: Reckoning with the Boundaries of Sex Discrimination Law," Columbia Journal of Gender and Law, vol. 18, 20o8; NATIONAL INSTITUTE OF JUSTICE, Practical Implications of Current Domestic Violence Research for Law Enforcement, Prosecutors and Judges, junio de 2009. En cuanto a la legislación española se refiere, véase, entre otros, ACALE SÁNCHEZ, M., "Los nuevos delitos de maltrato singular y de maltratos habituales en determinados ámbitos", en Revista de Derecho penal y Criminología, no 15, 2005;;; de la misma, "Violencia de género y Derecho penal de excepción: entre el discurso de la resistencia y el victimismo punitivo", en Cuadernos de Derecho Judicial, no 9 , 2007; p. 31 a 74; BOLDOVA PASAMAR, M., y RUEDA MARTÍN, M., (Coord.) La reforma penal en torno a la violencia doméstica y de género. Ed. Bosch. Barcelona, 2006; FARALDO CABANA, P., "Razones para la introducción de la perspectiva de género en Derecho penal a través de la Ley Orgánica 1/2004, de 28 de diciembre, sobre medias de protección integral contra la violencia de género", en Revista Penal, no 17, 2006; p. 72 a 94; CORCOY BIDASOLO, M., "Problemática jurídico-penal y político-criminal de la regulación de la violencia de género y doméstica”, en Revista de Derecho. Chile, 2010; disponible en www.scielo.cl/scielo. php?script=sci_arttext\&pid=So718-685120100oo10ooo9; NUÑEZ CASTAÑ, E., (Dir.) Estudios sobre la tutela penal de la violencia de género. Ed. Tirant lo Blanch. Valencia, 2009; de la misma, "La violencia doméstica en la legislación española: especial referencia al delito de maltrato habitual”, en Revista de Estudios de la Justicia, no 12. Universidad de Chile, 2010; p. 97 a 148; ROIG TORRES, M., "La delimitación de la 'violencia de género': un concepto espinoso”, en Estudios Penales y Criminológicos, vol. XXXII, 2012 ; p. 247 a 312. 
doméstica. Según el primero de los conceptos, se dará cuando exista "una violación de los derechos humanos y una forma de discriminación contra las mujeres, y designará todos los actos de violencia basados en el género que implican o pueden implicar para las mujeres daños o sufrimientos de naturaleza física, sexual, psicológica o económica, incluidas las amenazas de realizar dichos actos, la coacción o la privación arbitraria de libertad, en la vida pública o privada”. Mientras que por violencia doméstica debe entenderse "todos los actos de violencia física, sexual, psicológica o económica que se producen en la familia o en el hogar o entre cónyuges o parejas de hecho antiguos o actuales, independientemente de que el autor del delito comparta o haya compartido el mismo domicilio que la víctima".

Ahora bien, a pesar de esta claridad conceptual, frecuentemente, la violencia de género aparece íntimamente ligada, incluso, confundida, con la violencia intrafamiliar. Baste citar que, en Estados Unidos, VAWA define la violencia doméstica como "aquella en la que una persona es condenada por un delito 'cometido por un compañero íntimo, padre, madre o guardián de la víctima que requiere el uso o el intento de usar fuerza física o se amenaza con usar un arma mortal" ${ }^{\prime 8}$. Para el Departamento de Justicia se considera violencia doméstica el "patrón de conducta abusiva en cualquier relación que es usado por un miembro de la pareja para obtener o mantener podery control sobre el otro compañero íntimo. La violencia doméstica puede ser física, sexual, emocional, económica o psicológica en sus acciones o, incluso, pueden constituir amenazas actuaciones que influyen en la otra persona. Esto incluye cualquier comportamiento que intimide, manipule, humille, aísle, atemorice, coerza, amenace, culpabilice, hiera, injurie o cause daño a alguien"19. Conforme a estas definiciones y lineamientos, se entiende que un compañero íntimo lo es el cónyuge, el ex cónyuge, una persona que tenga un hijo en común con la víctima o una persona que conviva o haya convivido con la víctima.

En este sentido, cabe destacar que las sucesivas reformas de VAWA han servido para extender el ámbito de aplicación de la Ley, ya que es la catalogación de un hecho como de violencia doméstica lo que determina el acceso a los beneficios y al régimen de protección establecido. Así, en el año 2000, se incorporó la violencia en el noviazgo y el acoso como modalidad delictiva que integra esta categoría y, más recientemente, en 2013, se amplió las personas beneficiarias, incluyendo a mujeres indígenas, inmigrantes, victimas lesbianas, gays, bisexuales y transexuales, estudiantes universitarios y jóvenes y residentes de programas de vivienda pública.

Esta misma superposición entre los aspectos de género y de violencia doméstica se observa en la Ley Orgánica de Medidas de Protección Integral contra la Violencia de Género española. En la Exposición de Motivos se afirma que "se trata de una violencia que se dirige sobre las mujeres por el mismo hecho de serlo, por ser consideradas, por sus agresores, carentes de los derechos mínimos de libertad, respeto y capacidad de decisión", lo que hace que, por condicionantes socioculturales, se le asigne una posición de subordinación al hombre que se manifiesta, según puede leerse en el texto introductoria de la Ley, en los "tres ámbitos básicos de relación de la persona: maltrato en el seno de las relaciones de pareja, agresión sexual en la vida social y acoso en el medio laboral". Sin embargo, en el artículo 1.1. dispone que la presente Ley tiene como objeto actuar contra la violencia que, como manifestación de la discriminación, la situación de desigualdad y las relaciones de poder de los hombres sobre las mujeres, se ejerce sobre estas por parte de quienes sean o hayan sido sus cónyuges o de quienes están o hayan estado ligados a ellas por relaciones similares de afectividad, aún sin convivencia. Vemos, pues, que, a pesar de las declaraciones previas, esta Ley únicamente protege a la mujer en un determinado entorno: en relaciones de pareja presentes o ya extinguidas.

La equiparación entre violencia de género y violencia doméstica, aunque es muy común, resulta improcedente por cuanto que no todo acto de violencia familiar es violencia de género, ni todos los actos de violencia de género se producen en el ámbito familiar. En realidad, la regulación española actual, se refiere a supuestos de violencia doméstica en los que a la mujer, eso sí, se le dispensa una protección especial y reforzada. En cualquier caso se hace preciso señalar que, en lo que sigue, se hará una referencia conjunta a ambos fenómenos, por cuanto que, a los efectos que aquí interesan, la labor policial no establece distinción alguna.

18 Sección 922 (g) (9) de VAWA

19 Sobre tal cuestión, puede verse Departamento de Justicia de los Estados Unidos, Oficina de Violencia Doméstica (OVW), https://www. justice.gov/ovw/domestic-violence, oficina que fue creada, precisamente, para implementación de VAWA. 


\section{VIOLENCIA DE GÉNERO Y FUNCIÓN POLICIAL}

\subsection{La función policial en la normativa supranacional.}

Es cierto que no se encuentran referencias específicas en los textos internacionales a la labor policial. Esta ausencia no debe extrañar debido a la pretensión de generalidad que debe presidir un acuerdo de estas características. No obstante, sí se imponen ciertos deberes a los Estados en los que no es difícil incluir a la Policía como destinataria. Así, el artículo 4 c) de la Declaración sobre la eliminación de la violencia contra la mujer requiere a los Estados a adoptar políticas destinadas a eliminar la violencia contra la mujer y, con este objetivo, entre otras exigencias, obliga a proceder con la debida diligencia a fin de prevenir, investigar y, conforme a la legislación nacional, castigar todo acto de violencia contra la mujer, ya se trate de actos perpetrados por el Estado o por particulares. Idéntico mandato contiene el apartado b) del artículo 7 de la Convención Interamericana para prevenir, sancionar y erradicar la violencia contra la mujer y en parecidos términos se pronuncia el artículo 5.2 del Convenio del Consejo de Europa para prevenir y combatir la violencia contra las mujeres, en cuya virtud los Estados Parte han de adoptar las medidas legislativas y otras necesarias para "actuar con la diligencia debida para prevenir, investigar, castigar y conceder una indemnización por los actos de violencia incluidos en el ámbito de aplicación del presente Convenio cometidos por actores no estatales".

Además, se contienen previsiones en cuanto a la necesidad de formar a determinados profesionales. En este sentido, el apartado i) del artículo 4 de la Declaración sobre la eliminación de la violencia contra la mujer se refiere a "autoridades encargadas de hacer cumplir la ley y los funcionarios que han de aplicar las políticas de prevención, investigación y castigo de la violencia contra la mujer". El artículo 8 de la Convención Interamericana para prevenir, sancionar y erradicar la violencia contra la mujer alude a programas de educación y capacitación dirigidos al "personal en la administración de justicia, policial y demás funcionarios encargados de la aplicación de la ley, así como del personal a cuyo cargo esté la aplicación de las políticas de prevención, sanción y eliminación de la violencia contra la mujer" y, por último, el artículo 15 del Convenio del Consejo de Europa para prevenir y combatir la violencia contra las mujeres, de forma más genérica, determina a las Partes a impartir o reforzar la "formación adecuada de los profesionales pertinentes que traten con víctimas o autores de todos los actos de violencia" a los que se refiere el Convenio y, entre los que, sin duda, se encuentran los miembros de las Fuerzas y Cuerpos de Seguridad.

\section{LA SITUACIÓN EN ESTADOS UNIDOS}

Con anterioridad a la promulgación de VAWA, existía un debate acerca de la función policial en materia de violencia doméstica, pudiéndose distinguir tres posiciones distintas ${ }^{20}$. La primera sostenía que la intervención debía reducirse al mínimo posible, toda vez que los agresores no eran efectivamente castigados por el sistema de Justicia, pese a que pudiera haber existido una detención inicial. A ello se unía el convencimiento de que se trataba de un problema familiar ajeno, en consecuencia, al sistema de Administración de Justicia. En este sentido, debe tenerse en cuenta que antes de 1977, ninguno de los Estados tenía una legislación que permitiera arrestos policiales en casos de violencia doméstica, a no ser que un oficial de la policía hubiese sido testigo de la agresión para, de este modo, satisfacer el requisito de causa probable ${ }^{21}$. Una segunda tendencia, siguiendo las recomendaciones dadas por los psicólogos,

20 Sobre esta cuestión, puede verse, SHERMAN L., y Richard A. BERK, R. A., The Minneapolis Domestic Violence Experiment, abril de 1984, publicado por el Police Foundation, Washington D.C, http://www.google.com/url?sa=t\&rct=j\&q=the\%2ominneapolis\%2o domestic\%2oviolence\%2oexperiment\&source=web\&cd=1\&ved=oCCwQFjAA\&url=http\%3A\%2F\%2Fwww.policefoundation . org\%2Fpdf\%2Fminneapolisdve.pdf\&ei=5mahT9ClK4eg9QSeg5irCA\&usg=AFQjCNFM2DnkmVmg78RTEaAKqaoGYW_ RSw\&cad=rja.

21 ADLER, J. R., “Strengthening..., op. cit. 
considera oportuna una mayor intervención de la policía, mediando entre las partes y restaurando la paz sin necesidad de efectuar arrestos. Por último, los grupos feministas y el Foro Ejecutivo de Investigaciones de la Policía reivindicaban que la violencia doméstica debía ser tratada como un delito y, por tanto, la actuación policial debía conllevar el arresto del agresor.

En esta línea se inscribe el conocido como "Experimento Minneapolis", que es el más citado y el que mayor influencia ha ejercido en materia de política criminal de los últimos años en los Estados Unidos. Ello se debe a que, en parte, derivó en un cambio sustancial de la visión que la sociedad tenía de la violencia doméstica y, por otro lado, porque los resultados de este experimento arrojaron que el arresto constituía el mejory más eficaz de los métodos a disposición de la policía para reducir los casos de violencia doméstica. A partir de marzo de 1984, el Departamento de Policía de Minneapolis modificó su modus operandi y la detención del agresor se convirtió en una práctica habitual para este tipo de conflictos. Hubo programas de entrenamiento y concienciación para los policías que fueron formados bajo estas directivas. Otra consecuencia no menos importante de este estudio fue la puesta en evidencia de la necesidad de dotar a la policía de la autoridad suficiente para permitirle efectuar arrestos basados en la doctrina de la causa probable en casos de delitos leves de violencia doméstica, posibilidad ésta que fue incorporada posteriormente por varias legislaciones estatales ${ }^{22}$.

La aprobación en 1994 de VAWA supuso un impacto no solo en los departamentos policiales y su funcionamiento, sino también en las legislaturas estatales. A partir de entonces, se marca una particular diferencia histórica en el establecimiento de políticas de arresto en casos de violencia doméstica a nivel nacional y de manera generalizada. Ello se debe a que la normativa es clara al indicar que para recibir fondos federales, los Estados deben adoptar medidas que incluyan "(1) Implementar programas y políticas de arresto o pro-arresto obligatorio en los departamentos de policía, incluyendo programas de arresto obligatorio y políticas para la protección de otras violaciones". A ello se suma el hecho de que en 1996, el Congreso Norteamericano promulgó la Ley de Control del Crimen (Crime Control and Law Enforcement Act), como respuesta a la "epidemia de la violencia doméstica" que afecta todos los aspectos de la vida de las mujeres ${ }^{23}$. Esta Ley fue enmendada en 1998 y se introdujo la orden de restricción obligatoria durante 30 días.

De este modo, las políticas y procedimientos policiales empiezan a hacer ajustes en sus procedimientos desde una perspectiva más unificada e integral. Por citar un ejemplo, Massachusetts, en 1999, promulgó leyes dirigidas a la política de respuesta conocida como "arresto preferible", que obliga a la detención y emisión obligatoria de una orden de restricción en casos de violencia doméstica. Esta política de condena a la violencia doméstica se fue generalizando también gracias a la influencia de los medios de comunicación y a los éxitos conseguidos en las demandas interpuestas por mujeres contra algunos Departamentos de Policía por no ejecutar las leyes de protección en contra de sus parejas evidentemente violentas ${ }^{24}$.

Con todo, los cambios más evidentes se producen a partir del año 2000, ya que la modificación operada en VAWA constituye un hito en lo que se refiera a la función y formación policial en materia de violencia doméstica. En efecto, es en ese momento cuando se reconoce expresamente la necesidad de un cambio en la función policial y, necesariamente, en la formación policial. Para enfrentar la problemática, VAWA 2000 incrementa los fondos destinados a programas de asistencia para la prevención de la violencia doméstica, las agresiones sexuales y el acoso. Y, asimismo, se autoriza el gasto de tres billones de dólares para el apoyo de programas destinados a la formación policial, incluyendo el desarrollo de manuales y protocolos para hacer frente al problema. Dentro de este marco, una de las iniciativas más importantes es el denominado STOP (Services-Training-Officers-Prosecutors) que concede 925 millones de dólares para programas de apoyo a la policía, fiscalías, cortes y agencias de servicio a las víctimas; y 200 millones de dólares para asistencia legal a las víctimas que requieran la obtención de órdenes de protección y para proporcionar los servicios de refugios a las víctimas de este tipo de violencia.

Los Departamentos de Policía en Estados Unidos coinciden en afirmar que el mayor número

22 Para más información ver HANNA, C., "No Right...", op. cit.

23 Véase S. Con. Res. 66, 104th Cong. (1996).

24 Sirvan de ejemplo lo casos Scott v. Hart U.S. District Court for the Northen District of California; Bruno v. Codd 47 N.Y. 2 d. 582 , 393 N.E. 2d. 976, 419 N.Y.S. 2d. 901 (1979) y Thurman v. City of Torrigon 595 F. Supp. 1521 (1984). 
de llamadas a las Centrales de Policía están relacionadas con la violencia doméstica ${ }^{25}$. Es más, en el período comprendido entre 2010 y 2014, el 22\% de las muertes de los oficiales de policía en el ejercicio de sus funciones tuvieron lugar en intervenciones como respuesta a llamadas por delitos de violencia doméstica ${ }^{26}$. Las estadísticas indican, asimismo, que en una tercera parte de los homicidios de mujeres el autor es un compañero íntimo ${ }^{27}$. Consecuentemente, los departamentos policiales han desarrollado sus propias políticas y procedimientos para responder a estas solicitudes que incluyen la participación en programas de formación especializados y la creación de unidades dedicadas a la investigación de este tipo de infracciones.

En todos los casos, los protocolos policiales adoptados consideran que las llamadas por hechos relacionados con violencia domésticas merecen el tratamiento de altamente prioritarias o como situaciones de peligro para lavida. Esto tiene como consecuencia que muchos departamentos continúen con las investigaciones aún y cuando la víctima cancele la solicitud que pudiera haber hecho. Las peculiaridades de esta tipología delictiva aconsejan una intervención policial sumamente cuidadosa (uso de luces de emergencia discreto, observar y evaluar antes de anunciar la presencia policial y, en todo caso, adoptar medidas de precaución, mantener al agresor separado de la víctima y entrevistar a ambos por separado para obtener información y que la víctima pueda expresarse libremente, etc.). De singular importancia es la obtención de pruebas y la detección del nivel de riesgo en el que se encuentra la víctima. Por ello, algunos Departamentos de Policía requieren que se tomen fotografías de las lesiones de las víctimas y de la escena del crimen y que se graben todas las entrevistas con víctima y agresor, así como las de posibles testigos.

La gravedad del problema es evidente si se toma en consideración que en un estudio realizado por el Foro Ejecutivo de Investigación Policial (Police Executive Research Forum), en el que participaron 358 Departamentos policiales, se determinó que aplicando los protocolos actuales, en un $79 \%$ de casos, los oficiales pudieron incautar armas de fuego después de realizar las entrevistas en el lugar de los hechos ${ }^{28}$.

En otro orden de consideraciones, cabe recordar que los delitos de violencia doméstica son delitos estatales, no federales; por tanto, corresponde a los diferentes Departamentos de Policía de cada Estado su prevención e investigación y, a los correspondientes tribunales, su enjuiciamiento. Esta configuración presentaba un problema en materia de ejecución de órdenes judiciales de alejamiento o de protección a la víctima. Para poner fin a esta situación, VAWA 2000 estableció el 'total reconocimiento de buena fe y credibilidad' de todas las órdenes de protección emitidas en cualquier sede - civil, penal o por una tribu indígena - y ordenó que cada Estado reconociera las sanciones penales impuestas por otro Estado, así como las órdenes relativas a medidas de protección. Esta medida ha tenido como consecuencia que tales órdenes son de plena ejecución en una jurisdicción distinta de aquella que la emitió. En la actualidad, y como consecuencia de VAWA, cuarenta y siete Estados han promulgado legislación reconociendo las órdenes de protección de otras jurisdicciones y tres Estados (Alaska, Montana y Pennsylvania) requieren que una orden emitida fuera del territorio estatal, sea convalidada ante los tribunales locales con carácter previo a ser ejecutada.

A modo de recapitulación, podría decirse que VAWA ha promovido fundamentalmente programas dirigidos a la capacitación de policías y fiscales, ha ampliado el número de unidades especializadas en violencia doméstica en las oficinas de la policía y de la fiscalía, ha impulsado el desarrollo e implementación de políticas y directrices más efectivas para la investigación y persecución de estos delitos y ha mejorado, asimismo, los sistemas de obtención de información y de comunicación, incluyendo el delito de acoso (stalking).

${ }_{25}$ FRIDAY, P., LORD, V., EXUM, M., y HARTMAN, J., “Evaluating the Impact of a Specialized Domestic Violence Police Unit." National Institute of Justice, Washington, DC: U.S. Department of Justice, Mayo 2006.

26 BRUEL, N., y SMITH, M., Office of Community Oriented Policing Services, U.S. Department of Justice and National Law Enforcement Officers Memorial Fund, "Deadly Calls and Fatal Encounters", 2015.

27 Homicide Trends in the United States, 1980-2008. Nov, 2011. U.S. Department of Justice, Office of Justice Programs, Bureau of Justice Statistics.

28 Véase, Subject to Debate, A Newsletter of the Police Executive Research Forum, Vol. 29, No. 1, Enero//Febrero 2015. 


\section{LA SITUACIÓN EN ESPAÑA}

El artículo 104 de la Constitución Española establece que será misión de las Fuerzas y Cuerpos de Seguridad proteger el libre ejercicio de los derechos y libertades y garantizar la seguridad ciudadana. A ello se le suman las funciones de averiguación del delito y descubrimiento y aseguramiento del delincuente que el artículo 126 del mismo texto encomienda a la Policía Judicial ${ }^{29}$. Pues bien, a estos cometidos de carácter general, hay que sumar las previsiones específicas que, en materia de violencia de género, contempla la Ley Orgánica 1/2004 de Medidas de Protección Integral contra la Violencia de Género.

Así, el artículo 31.1 dispone que el Gobierno "establecerá, en las Fuerzas y Cuerpos de Seguridad del Estado, unidades especializadas en la prevención de la violencia de género y el control de la ejecución de las medidas judiciales adoptadas". Lo cierto es que el Cuerpo Nacional de Policía contaba ya desde 1986 con el Servicio de Atención a la Mujer (SAM), encuadrado en el Servicio de Atención a la Familia (SAF), perteneciente orgánicamente a Policía Judicial con competencia, por tanto, en investigación y persecución de estos delitos. Por otra parte, dentro de la Unidad Central de Seguridad Ciudadana, se crearon en 2003 las Unidades de Prevención, Asistencia y Protección contra los Malos tratos a la Mujer (UPAP), cuyo principal cometido es la prevención y la protección de las víctimas. La Orden INT/2678/2015, de 11 de diciembre, por la que se modifica la Orden INT/28/2013, de 18 de enero, por la que se desarrolla la estructura orgánica y funciones de los Servicios Centrales y Periféricos de la Dirección General de la Policía, pone fin a esta dualidad creando la Unidad Central de Atención a la Familia y Mujer (UFAM), que, en el seno de la Comisaría General de Policía Judicial, asume las competencias en la investigación y persecución de las infracciones penales en el ámbito de la violencia de género, doméstica y todos los delitos sexuales junto con la coordinación de la actividad de protección de las víctimas de violencia de género ${ }^{30}$. Con la unificación de las actuaciones en materia de prevención, investigación y protección de la víctima se persigue dar una aumentar la eficacia a través de una respuesta coordinada, inmediata y continua. Por su parte, la Guardia Civil encomienda estas funciones al Equipo Mujer-Menor (EMUME), creados en 1995, cuya labor se encuadra en la Sección de Investigaciones de las Unidades Orgánicas de Policía Judicial.

Vemos, pues, que la actuación policial en relación con la violencia de género - aunque también doméstica - se centra en tres ámbitos de actuación: prevención, investigación y protección de las víctimas ${ }^{32}$. Precisamente, en relación con esta última competencia, el apartado segundo del artículo 31 de la Ley Orgánica 1/2004 de Medidas de Protección Integral contra la Violencia de Género, insta el Gobierno a promover la cooperación de las Policías Locales33, con el fin de lograr una protección más eficaz de las víctimas y este es, asimismo, el objetivo que persigue la aplicación de las disposiciones contenidas en el referido precepto a las

29 Esta previsión se complementa con lo dispuesto en el artículo 282 de la Ley de Enjuiciamiento Criminal, en el que se afirma que la Policía Judicial tiene por objeto y será obligación de todos los que la componen, averiguar los delitos públicos que se cometieren en su territorio o demarcación; practicar, según sus atribuciones, las diligencias necesarias para comprobarlos y descubrir a los delincuentes, y recoger todos los efectos, instrumentos o pruebas del delito de cuya desaparición hubiere peligro, poniéndolos a disposición de la autoridad judicial. Cuando las víctimas entren en contacto con la Policía Judicial, cumplirá con los deberes de información que prevé la legislación vigente. Asimismo, llevarán a cabo una valoración de las circunstancias particulares de las víctimas para determinar provisionalmente qué medidas de protección deben ser adoptadas para garantizarles una protección adecuada, sin perjuicio de la decisión final que corresponderá adoptar al Juez o Tribunal. Por su parte, el artículo 549 de la Ley Orgánica 6/1985, de 1 de julio, del Poder Judicial, señala las funciones específicas que le corresponde, a saber: a) La averiguación acerca de los responsables y circunstancias de los hechos delictivos y la detención de los primeros, dando cuenta seguidamente a la autoridad judicial y fiscal, conforme a lo dispuesto en las leyes; b) El auxilio a la autoridad judicial y fiscal en cuantas actuaciones deba realizar fuera de su sede y requieran la presencia policial; c) La realización material de las actuaciones que exijan el ejercicio de la coerción y ordenare la autoridad judicial o fiscal; d) La garantía del cumplimiento de las órdenes y resoluciones de la autoridad judicial o fiscal; y, e) Cualesquiera otras de la misma naturaleza en que sea necesaria su cooperación o auxilio y lo ordenare la autoridad judicial o fiscal.

30 Artículo 3 de la Orden INT/2678/2015, de 11 de diciembre. Disponible en https://www.boe.es > BOE > 15/12/2015.

31 Sobre las labores que desarrolla el Instituto Armado en esta materia, puede verse IGUAL GARRIDO, C., "Actuación de la Guardia Civil ante la violencia de género", en Cuadernos de la Guardia Civil no 51, 2015; p. 26 y ss.

$32 \mathrm{Al}$ respecto, puede verse La intervención policial en casos de violencia de género. Disponible en www.interiuris.org/archivos/ Actuacion_policial_Violencia_de_Genero.pdf

33 Para hacer posible esta colaboración, los Ayuntamientos pueden firmar un Acuerdo con el Ministerio del Interior y, de este modo, participar en el ejercicio de las funciones de Policía Judicial. El 20 de febrero de 2007 se firmó un Convenio Marco con la Federación Española de Municipios y Provincias. 
Comunidades Autónomas que cuenten con cuerpos de policía que desarrollen las funciones de protección de las personas y bienes y el mantenimiento del orden y la seguridad ciudadana dentro del territorio autónomo (artículo 31.4 Ley Orgánica 1/2004 de Medidas de Protección Integral contra la Violencia de Género).

Las fuerzas y Cuerpos de Seguridad son, en consecuencia, los encargados de velar por el cumplimiento de las decisiones judiciales adoptadas, remitiéndose a tal efecto a las que contiene la propia Ley ${ }^{34}$, y a las prohibiciones de residir o acudir a un determinado lugar, aproximarse o comunicarse con determinadas personas, que pueden imponerse como medida de naturaleza cautelar ${ }^{35} \mathrm{o}$ como pena accesoria tras la realización de un hecho constitutivo de delito ${ }^{36}$. Al respecto cabe señalar que, tras la reforma operada en el Código penal por medio de la Ley Orgánica 15/2003, de 25 de noviembre, los jueces y tribunales, según lo dispuesto en el apartado segundo del artículo 57 del Código penal, habrán de imponer en todo caso la pena de aproximación a la víctima o a sus familiares en el supuesto de que se haya cometido alguno de los delitos que se especifican ${ }^{37}$ contra determinadas personas ${ }^{38}$. De este modo, con la aplicación preceptiva se impide que el juez decida acerca de la necesidad y pertinencia de esta medida valorando las circunstancias del caso concreto y, lo que es más importante, se priva a la mujer del derecho a seguir o reanudar su relación de pareja puesto que es absolutamente irrelevante su consentimiento e, incluso, puede hacerse en su contra ${ }^{39}$.

Pero es que, además, sin abandonar el ámbito de protección, a las unidades policiales les corresponde valorar la situación de riesgo en la que se encuentra la víctima y, en función de este nivel ${ }^{40}$, habrán de adoptar las medidas policiales de seguimiento y protección correspondientes y, asimismo, servirán a los jueces como criterio para decidir acerca de la imposición de alguna medida cautelar. A tales efectos, se cuenta desde julio de 2016 con un nuevo Protocolo para la Valoración Policial del nivel de riesgo de Violencia de Género y de Gestión de la Seguridad de las Víctimas ${ }^{41}$ que actualiza los formularios - Valoración Policial del Riesgo (VPR) y Valoración Policial de Evolución del Riesgo (VPER) - que se incluyen en el Sistema de Seguimiento Integral de los Casos de Violencia de Género (VioGén) de la Secretaría de Estado de Seguridad del Ministerio del Interior.

Una vez delimitadas las funciones que competen a las Fuerzas y Cuerpos de Seguridad, se hace preciso señalar que el artículo 31.3 de la Ley Orgánica 1/2004 de Medidas de Protección Integral contra la Violencia de Género, dispone que su actuación han de tener en cuenta el Protocolo de Actuación de las Fuerzas y Cuerpos de Seguridad y de Coordinación con los Órganos Judiciales para la protección de

\footnotetext{
34 Recogidas en el Capítulo IV del Título V dedicado a la Tutela Judicial. 35 Artículo 544 bis de la Ley de Enjuiciamiento Criminal.

36 Artículo 57 del Código penal.

37 Homicidio, aborto, lesiones, contra la libertad, de torturas y contra la integridad moral, trata de seres humanos, contra la libertad e indemnidad sexuales, la intimidad, el derecho a la propia imagen y la inviolabilidad del domicilio, el honor, el patrimonio y el orden socioeconómico.

38 En concreto, el precepto se refiere a quien sea o haya sido el cónyuge, o sobre persona que esté o haya estado ligada al condenado por una análoga relación de afectividad aun sin convivencia, o sobre los descendientes, ascendientes o hermanos por naturaleza, adopción o afinidad, propios o del cónyuge o conviviente, o sobre los menores o personas con discapacidad necesitadas de especial protección que con él convivan o que se hallen sujetos a la potestad, tutela, curatela, acogimiento o guarda de hecho del cónyuge o conviviente, o sobre persona amparada en cualquier otra relación por la que se encuentre integrada en el núcleo de su convivencia familiar, así como sobre las personas que por su especial vulnerabilidad se encuentran sometidas a su custodia o guarda en centros públicos o privados.

39 La irrelevancia que, en estos casos, se concede a la voluntad de la víctima ha hecho que se cuestione la constitucionalidad de esta disposición. El Tribunal Constitucional en la sentencia 6o/2010, de 7 de octubre, se pronunció al respecto y afirma que no vulnera el principio de personalidad de la penas por cuanto que esta medida restringe los derechos del condenado y sólo de manera colateral afecta a la víctima. Además, se considera prioritaria la protección de la víctima y, por tanto, concluye que el artículo 57.2 del Código penal responde a fines constitucionalmente legítimos. Sobre esta cuestión, puede verse, entre otros, VALEIJE ALVÁVEZ, I., "Penas accesorias, prohibiciones del art. 48.2 CP y delito de quebrantamiento de condena. Consideraciones críticas sobre al artículo 57.2 del CP", en Estudios Penales y Criminológicos, no 26, 2006; p. 321 a 354; MAYORDOMO RODRIGO, V., "Reflexiones sobre la obligatoriedad de las órdenes de alejamiento en determinados delitos”, en Eguzkilore, no 23, 2009; p. 261 a 268; FARALDO CABANA, P., "La pena de prohibición de aproximarse a la víctima o a otras personas", en FARALDO CABANA, P., y PUENTE ABA, L. M., Las penas privativas de derechos y otras alternativas a la privación de libertad. Ed. Tirant lo Blanch. Valencia, $2013 ;$ p. 295 a 319. 40 Se distinguen cinco estadios diferentes que van desde el peligro no apreciado hasta riesgo extremo y se prevén distintas medidas, unas obligatorias y otras complementarias, proporcionadas a cada situación.

41 Instrucción 7/2016, de la Secretaria de Estado de Seguridad. Texto íntegro en file:///Users/useruji/Downloads/2016o823\%20 Instrucci $\% \mathrm{C}_{3} \% \mathrm{~B}_{3}$ \% $207-2016 \% 20$ Secretar\%C3\%ADa\%2ode\%2oEstado\%2ode\%2oSeguridad.pdf
} 
las víctimas de violencia doméstica y de género ${ }^{42}$. Este documento contiene previsiones acerca de cómo operar desde el mismo momento en el que se tiene conocimiento de hechos que podrían ser delictivos y que se refieren a aspectos que van desde la valoración de la situación de riesgo a las comunicaciones con los órganos judiciales, pasando por la recogida de la denuncia y la elaboración del atestado o el control de las medidas de protección, aseguramiento o alejamiento. Interesa destacar que, en consonancia con el enfoque integral que caracteriza esta Ley, se pretende mejorar las comunicaciones con los órganos jurisdiccionales a través del establecimiento de un sistema ágil de intercambio de información bidireccional. En este sentido, el artículo 32 de la Ley Orgánica 1/2004 de Medidas de Protección Integral contra la Violencia de Género, constituye una muestra más del convencimiento de que no es posible enfrentar este problema desde una única perspectiva, al conminar a los poderes públicos a elaborar planes de colaboración que garanticen la adecuada ordenación de todas las iniciativas que se lleven a cabo en materia de prevención, asistencia y persecución de los actos de violencia de género y que involucran, además de a las Fuerzas y Cuerpos de Seguridad, a las Administraciones sanitarias, a la Administración de Justicia y a los servicios sociales y organismos de igualdad ${ }^{43}$.

No puede ponerse fin a este apartado sin hacer una referencia, por escueta que sea, al Manual de Buenas Prácticas Policiales en materia de Violencia de Género ${ }^{44}$. Este modelo de práctica policial, elaborado por expertos policiales de varios Estados miembros, fue aprobado por el Consejo de la Unión Europea el 9 de abril de 2010 y nace con la vocación de servir de marco de referencia para la actuación policial frente a este tipo de delincuencia. Con este propósito, define una buena práctica policial como "toda actividad o grupo de actuaciones policiales integradas en una estrategia o un plan de acción global que, de conformidad con los principios de eficiencia, calidad y excelencia en el servicio, estén destinadas a prevenir el comportamiento violento contra las mujeres y a coordinar las medidas de protección y de bienestar necesarias para impedir que la víctima sufra otros ataques". Para ello, se proponen metodologías de trabajo que optimicen la actuación policial centrada prioritariamente en la prevención, la protección y la asistencia a la víctima de violencia de género. Asimismo, se fomenta la formación especializada de los funcionarios de policías y se establecen mecanismos de coordinación con otras instituciones posibilitando una respuesta integral y, en consecuencia, más eficaz a esta lacra social.

Finalmente, en la Ley Orgánica 1/2004 de Medidas de Protección Integral contra la Violencia de Género se encuentra una última mención a las Fuerzas y Cuerpos de Seguridad referida, esta vez, a la formación. En efecto, según dispone el artículo 47, las instituciones competentes habrán de asegurar "una formación específica relativa a la igualdad y no discriminación por razón de sexo y sobre violencia de género" en los cursos que reciban. Sólo así, con una formación adecuada que permita una mayor y mejor comprensión de todos los aspectos que inciden en este fenómeno y, fundamentalmente, que empatice con la víctima se estará en condiciones de garantizar el mejor de los servicios.

\section{VIOLENCIA GÉNERO Y RESPONSABILIDAD ESTATAL}

Como se recordará, los textos supranacionales a los que se ha hecho referencia, requieren que los Estados procedan con la debida diligencia en la prevención, investigación y castigo de la violencia contra la mujer. Es más, del incumplimiento de este deber puede derivar responsabilidades para el Estado como así ha declarado la Corte Interamericana de Derechos Humanos en la paradigmática sentencia del caso conocido como "Campo Algodonero", de 16 de noviembre de 2009 "45. En él se enjuicia

$\overline{42}$ Disponible en http://www.violenciagenero.msssi.gob.es/profesionalesInvestigacion/juridico/protocolos/docs/Protocolo_ Actuacion_Fuerzas_Cuerpos_Seguridad_Coordinacion_Organos_Judiciales.pdf

43 A idéntica filosofía responde la Estrategia Nacional para la erradicación de la Violencia de Género (2013-2016). Documento disponible en http://www.violenciagenero.msssi.gob.es/laDelegacionInforma/pdfs/EstrategiaNacional.pdf

44 Puede consultarse el texto en http://www.interior.gob.es/documents/642012/1626283/Manual_UE_Buenas_Practicas_contra_ VdG.pdf/ae62b3f8-a54c-4728-9221-4b41ab719524

45 Un comentario de este fallo, puede verse en ABRAMOVICH, V., "Responsabilidad estatal por violencia de género: comentarios sobre el caso 'Campo Algodonero' en la Corte Interamericana de Derechos Humanos”; disponible en justiciaygenero.org.mx/wp- 
la responsabilidad estatal por la desaparición y posterior muerte de tres mujeres en Ciudad Juárez (México), debido a la falta de protección y a la no adopción de medidas preventivas - pese a tener constancia de la existencia de un patrón de violencia de género en la zona - y, lo que es más grave, la ausencia de una respuesta de las autoridades ante la desaparición y la negligencia absoluta en la investigación de los crímenes.

El Tribunal estima que el artículo 7 de la Convención Interamericana para prevenir, sancionar y erradicar la violencia contra la mujer sitúa al Estado en una posición de garante y, en consecuencia, tiene la obligación de adoptar políticas de prevención y prácticas que permitan una actuación eficaz en caso de denuncia. De este modo, además de prevenir los factores de riesgo, ha de fortalecer las instituciones con el fin de dar un tratamiento efectivo a la violencia de género. En aplicación de la doctrina del riesgo previsible y evitable, concluyó que México no contaba con normas o medidas que permitieran ofrecer una respuesta inmediata y eficaz ante las denuncias de desaparición y prevenir adecuadamente la violencia contra la mujer. Tampoco se demostró que se hubiera adoptado medida alguna tendente a depurar la responsabilidad de los funcionarios responsables de recibir las denuncias de los familiares y no cabe duda, como la Corte recuerda, que la impunidad fomenta la reiteración de estos lamentables sucesos y la indefensión de las víctimas.

Es cierto que no todos los supuestos de inobservancia de las obligaciones asumidas alcanza la trascendencia que los hechos a los que se refiere la sentencia y que, como es sabido, se inscriben en un contexto generalizado y estructural de violencia de género. Pero no lo es menos que cualquier incumplimiento grave del deber de diligencia habría de originar la responsabilidad del Estado pues, como ha reconocido el Tribunal Europeo de Derechos Humanos, las obligaciones no se limitan a proveer de un marco legislativo destinado a prevenir y castigar el maltrato, sino que cuando se tiene conocimiento de un riesgo inminente de malos tratos o cuando ya se han producido estos episodios, le compete aplicar esas leyes para proteger a las víctimas y castigar a los responsables ${ }^{46}$.

En Estados Unidos, inicialmente, VAWA permitía que las víctimas de violencia doméstica pudieran acudir a la jurisdicción civil para demandar a los Departamentos de Policía por los daños que hubiesen sufrido. Esta posibilidad originó la interposición de varias demandas. Una resolución de la Corte Suprema de Justicia del año 200o, en el caso Brzonkala v. Morrison declaró, sin embargo, que no existía un derecho fundamental en materia de violencia doméstica, al considerar que el Congreso se había excedido en sus funciones al emitir el Subtítulo C de VAWA, 42 U.S. C. SS13981 ${ }^{47}$. Este fallo motivó un cambio importante aunque, desde luego, no excluye posibilidad de interponer demandas cuando se produzca la inobservancia o un incumplimiento de deberes.

Por lo que se refiere a España, la implicación del Estado en la defensa de los derechos de las mujeres y en la erradicación de la violencia de género queda patente en la Exposición de Motivos que acompaña a la Ley Orgánica 1/2004, de 28 de diciembre, de Medidas de Protección Integral contra la Violencia de Género. Como allí puede leerse, "los poderes públicos no pueden ser ajenos a la violencia de género, que constituye uno de los ataques más flagrantes a derechos fundamentales como la libertad, la igualdad, la vida, la seguridad y la no discriminación proclamados en nuestra Constitución". Ahora bien, pese a ese rotundo reconocimiento, y aunque el texto constitucional establece en el artículo 106.2 el derecho de los particulares a ser indemnizados por la lesión que sufran en cualquiera de sus bienes y derechos como consecuencia del funcionamiento de los servicios públicos, lo cierto es que, hasta la fecha, no se ha declarado la responsabilidad patrimonial de la Administración en aquellos supuestos en los que la víctima se le ocasiona algún daño como consecuencia del quebrantamiento de alguna de las medidas de protección adoptadas y, por tanto, cuando se encuentra "tutelada".

content/uploads/2015/o4/27.pdf; VÁZQUEZ CAMACHO, S. J., "El caso ‘Campo Algodonero’ ante la Corte Interamericana de Derechos Humanos", en Anuario Mexicano de Derecho Internacional. Vol. XI, 2011; p. 515 y ss.; disponible en https://revistas.juridicas.unam. $\mathrm{mx} /$ index.php/derecho-internacional/article/view/361/623.

46 Sentencias del Tribunal Europeo de Derechos Humanos Denis Vasilyev contra Rusia, de 17 de diciembre de 2009; E. M. contra Rumanía, de 30 de octubre de 2012; o Busuioc contra República de Moldavia, de 28 de mayo de 2013.

47 Brzonkala v. Morrison, 529 U.S. 598, 120 S.Ct. 1740,146 L. Ed 2d658 (2000). 
De cita ineludible es el caso A. González Carreño contra España que dio lugar al Dictamen de 16 de julio de 2014 del Comité para la Eliminación de la Discriminación contra la Mujer de Naciones Unidas ${ }^{48}$. En él se reconoce que España actuó negligentemente por no haber protegido a una niña asesinada por su padre (que posteriormente se suicidó) durante un régimen de visitas sin vigilancia, a pesar de que el progenitor tenía antecedentes por malos tratos y la madre había presentado más de 30 denuncias y, asimismo, solicitado órdenes de alejamiento que se incumplían sistemáticamente. Ante el caso omiso que se hizo a las advertencias del peligro que existía para la vida de la niña, la madre consideró que había habido una actuación negligente y presentó ante el Ministerio de Justicia una reclamación de responsabilidad patrimonial del Estado por anormal funcionamiento de la Administración de Justicia; petición que, no obstante, fue rechazada. Tampoco sus reclamaciones fueron atendidas ni por la Audiencia Nacional, ni en casación ante el Tribunal Supremo; razón por la que recurrió en amparo ante el Tribunal Constitucional, órgano que inadmitió el recurso aduciendo que el asunto carecía de relevancia constitucional.

Agotada la vía jurisdiccional nacional, se presentó en septiembre de 2012 una denuncia ante el Comité para la Eliminación de la Discriminación contra la Mujer en la que solicitaba la declaración de responsabilidad del Estado por no actuar con la diligencia debida para prevenir, investigar, juzgar y castigar la violencia ejercida por el varón y, tras el asesinato de la menor, por no dar una respuesta judicial efectiva, ni una reparación por los daños sufridos como consecuencia de este actuar negligente. El Comité formula al Estado una serie de recomendaciones de carácter general y, en atención a la pretensión solicitada, reconoce el derecho a obtener una reparación adecuada y una indemnización integral y proporcional a la gravedad de la conculcación de sus derechos. Asimismo, exhorta a llevar a cabo una investigación exhaustiva e imparcial para determinar la existencia de fallos en las estructuras y prácticas estatales que impidieron garantizar la protección de la víctima.

Lamentablemente, la respuesta del Estado español no por esperada es menos decepcionante. Se insiste en la inexistencia de base jurídica para indemnizar a la demandante y se escuda en el plazo de tiempo transcurrido desde los hechos (24 de abril de 2003) para rehusar abrir una nueva investigación, aunque, eso sí, se afirma que no se aprecian en la actualidad fallos estructurales o sistémicos del ordenamiento jurídico, ni tampoco adolece de escasez de medios personales o materiales que permitan evitar la reiteración de estos comportamientos ${ }^{49}$. Es verdad que las resoluciones del Comité no tienen carácter vinculante, ni son directamente ejecutables, pero no es menos cierto que el incumplimiento de las recomendaciones particulares empaña los, sin duda, encomiables logros conseguidos en esta materia - y que la respuesta ofrecida se encarga de poner de manifiesto - y, asimismo, contradice el compromiso asumido, y tan paladinamente declarado, en la defensa de los derechos de las mujeres víctimas de violencia de género.

\section{CONSIDERACIONES FINALES}

Sin desconocer las importantes metas alcanzadas y reconociendo, asimismo, los considerables esfuerzos realizados en orden a tratar de poner fin a la violencia de género, lo cierto es que las cifras son desalentadoras y no parece que la solución esté cerca.

Según las estadísticas del Departamento de Justicia de los Estados Unidos, en el año 200o, se reportaron a la policía, más o menos un cuarto de las agresiones físicas, una quinta parte de las violaciones y la mitad de todos los casos de acoso en los que la víctima era una mujer y el victimario, un compañero íntimo ${ }^{50}$; por lo que puede afirmarse que se trata de uno de los delitos que menos se pone en conocimiento

48 Puede consultarse el texto íntegro en http://www.rednosotrasenelmundo.org/IMG/pdf/Gonzalez_Carre_o_c-_Espa_a.pdf 49 Puede verse la respuesta íntegra del Estado Español al Comité para la Eliminación de la Discriminación contra la Mujer en www2. womenslinkworldwide.org/wlw/bajarFS.php?tl=3\&per $=218$

50 National Institute of Justice and the Centers of Disease Control and Prevention, Extent, Nature and Consequences of Intimate Partner Violence: Findings from the National Violence Against Women Survey, (200o). 
de las fuentes oficiales ${ }^{51}$ y ello, a pesar, de la importante incidencia práctica del fenómeno, como así atestigua el hecho de que las llamadas por violencia doméstica supongan un porcentaje significativo (entre un $15 \%$ y más del 50\%) de las llamadas que recibe la policía ${ }^{52}$. Es más, según cálculos del Centro para el Control de Enfermedades, realizados en 2010, una de cada cuatro mujeres y uno de cada siete hombres van a ser víctimas de violencia física severa de parte de su compañero íntimo en su vida, una de cada 10 mujeres en los Estados Unidos será víctima de violación por parte de de su compañero íntimo en su vida. Aproximadamente, el $16.9 \%$ de las mujeres y el $8 \%$ de los hombres, sufrirán algún tipo de delito de violencia sexual, por parte de su pareja. Al menos un $10.7 \%$ de las mujeres y un $2.1 \%$ de los hombres han sido víctimas de acoso por parte de su compañero íntimo en su vida. Finalmente, cerca de la mitad de todos los hombres y mujeres en este país experimentará una agresión psicológica por parte del compañero sentimental. Estos datos aparecen reflejados en el diagnóstico que realizara el Centro Nacional de Recursos contra la Violencia Sexual. Este organismo publicó un estudio en 2012, en el que concluía que la efectividad de los programas de prevención de la violencia doméstica radica en la diversidad de enfoques, participación comunitaria y en la educación, por lo que, consecuentemente, los programas que incluyen la respuesta coordinada y el trabajo multidisciplinario de diversas agencias de la comunidad se han convertido en el nuevo paradigma del tratamiento que se asigna a los casos de violencia intrafamiliar, violencia juvenil y violencia contra el adulto mayor.

Tampoco en España, atendiendo al número de mujeres muertas, puede decirse que la situación haya mejorado significativamente. Al respecto, piénsese que en 2003 y 2004 - años inmediatamente anteriores a la aprobación de la Ley Orgánica 1/2004, de 28 de diciembre - fallecieron 71 y 72 mujeres, respectivamente. En 2016, han perdido la vida 53 mujeres ${ }^{53}$, a lo que hay que sumar los ataques que no acaban en muerte. La respuesta, invariablemente, ha consistido en un endurecimiento intensivo y extensivo de la respuesta penal pero, además, se trata de un recurso desenfocado por cuanto que, como ha señalado GONZÁLEZ CUSSAC, se convierte la violencia de género en un problema de violencia doméstica con lo que se esconde la verdadera causa del problema que no es otra que una estructura social basada todavía en el dominio patriarcal54. De ahí que resulte prioritario enfatizar la adopción de medidas preventivas eficaces y fomentar políticas de igualdad.

En cualquier caso, no puede desconocerse que esta diferenciación obligaría a las Fuerzas y Cuerpos de Seguridad a indagar si los atentados que sufren las mujeres son expresión de la violencia machista por lo que, en consecuencia, debe quedar probada la situación de discriminación, subordinación y dominación a la que se somete a la mujer; o, por el contrario, se trata de episodios violentos fruto del deterioro de las relaciones interpersonales que, sin embargo, no persiguen la lesión de su integridad moral ni suponen un menoscabo a su dignidad55.

De lo que no cabe duda es de la encomiable labor que la policía viene realizando y que, según un estudio realizado recientemente ${ }^{56}$, merece una valoración muy positiva por parte de las víctimas. Realmente, son notorios los avances, pero también es mucho lo que queda por hacer. Posiblemente, en España, el principal reto consista en subsanar las deficiencias advertidas respecto de la responsabilidad de los entes públicos en caso de un funcionamiento negligente o anómalo de los servicios con competencia en esta materia. La asunción de esta responsabilidad, además de ser el reverso de los derechos que se le reconocen a la víctima ${ }^{57}$, constituiría una prueba irrefutable de que el férreo compromiso adquirido por el Estado en la erradicación de la violencia de género trasciende de las palabras de la Ley.

${ }_{51}$ U.S. Department of Justice, Bureau of Justice Statistics, “Criminal Victimization,” 2003

52 FRIDAY, P., LORD, V., EXUM, M., y HARTMAN, J., "Evaluating..., op. cit.

53 Datos disponibles en el Portal Estadístico de la Delegación del Gobierno para la Violencia de Género (estadisticasviolenciagenero. msssi.gob.es)

54 GONZÁLEZ CUSSAC, J. L., “La intervención...”, op. cit.

55 Sobre este aspecto, véase, RAMÓN RIBAS, E., "Los delitos de violencia de género según la jurisprudencia actual”, en Estudios Penales y Criminológicos, no 33, 2013; p. 401 a 464. Disponible en http://www.usc.es/revistas/index.php/epc/article/view/1323

56 GONZÁLEZ, J. L., y GARRIDO, M. J., "Satisfacción de las víctimas de violencia de género con la actuación policial en España.

Validación del Sistema VioGen”, en Anuario de Piscología Jurídica 2015, p. 29 y ss; disponible en www.sciencedirect.com/science/ article/pii/S1133074015000045

57 RUIZ-RICO RUİZ, C. “Aproximación a los nuevos retos jurídicos de la violencia de género: la responsabilidad pública”, en Derecho y cambio social, 2014; p. 10; disponible en https://dialnet.unirioja.es/descarga/articulo/5472798.pdf 


\section{REFERENCIAS}

BOIX REIG, J. y MARTÍNEZ GARCÍA, E., La nueva Ley contra la Violencia de Género. L. O. 1/2004, de 28 de diciembre. Ed. Iustel. Madrid, 2005.

BRUEL, N.; y SMITH, M.; Office of Community Oriented Policing Services. U.S. Department of Justice and National Law Enforcement Officers Memorial Fund. Deadly Calls and Fatal Encounters, 2015.

ESTIARTE. Carolina Villacampa. "El maltrato singular cualificado por razón de género. Debate acerca de su constitucionalidad”, en Revista Electrónica de Derecho Penal y Criminología, 2007.

FARALDO CABANA, P.; y PUENTE ABA, L. M., Las penas privativas de derechos y otras alternativas a la privación de libertad. Ed. Tirant lo Blanch. Valencia, p. 295 a 319, 2013.

FUENTES SORIANO, O. "La constitucionalidad de la Ley Orgánica de medidas de protección integral contra la violencia de género", en La Ley, no 5, 2005; p. 1153 a 1170;

FRA. EUROPEAN UNION AGENCY FOR FUNDAMENTAL RIGHTS. Violence against women: an EUwide survey, 2015. Disponible en: <http://fra.europa.eu/sites/default/files/fra-2014-vaw-survey-mainresults-apr14_en.pdf>. Acceso en: 05 jan. 2018.

FRIDAY, P.; LORD, V.; EXUM, M.; y HARTMAN, J., Evaluating the Impact of a Specialized Domestic Violence Police Unit. National Institute of Justice, Washington, DC: U.S. Department of Justice, Mayo 2006.

GOBIERNO DE ESPAÑA. Ley Orgánica 1/2004, de 28 dediciembre, de Medidas de Protección Integral contra la Violencia de Género. Disponible en: <https://www.boe.es/buscar/act.php?id=BOE-A-2004-2176o > . Acceso en: 05 jan. 2018.

GONZÁLEZ CUSSAC, J. L., "La intervención penal contra la violencia de género desde la perspectiva del principio de proporcionalidad", en Tutela procesal frente a la violencia de género. Universitat Jaume I. Castellón, 2007.

GONZÁLEZ, J. L., y GARRIDO, M. J., Satisfacción de las víctimas de violencia de género con la actuación policial en España. Validación del Sistema VioGen, en Anuario de Piscología Jurídica, 2015, p. 29 y ss. Disponible en: <www.sciencedirect.com/science/article/pii/S1133074015000045>. Acceso en: 05 jan. 2018.

HANNA, C. No Right to Choose: Mandated Victim Participation in Domestic Violence Prosecution. Harvard Law Revue. 1849, 1857-62. 1996.

IGUAL GARRIDO, C., "Actuación de la Guardia Civil ante la violencia de género", en Cuadernos de la Guardia Civil. no 51 , 2015; p. 26 y s.

LAURENZO COPELLO, P., "La violencia de género en la Ley Integral. Valoración político criminal “, en Revista Electrónica de Derecho penal y Criminología, 2005. Disponible en: <http://criminet.ugr.es/ recpc/o7/recpco7-08.pdf >. Acceso en: 05 jan. 2018. 
MAYORDOMO RODRIGO, V., Reflexiones sobre la obligatoriedad de las órdenes de alejamiento en determinados delitos, en Eguzkilore, no 23, p. 261 a 268, 2009.

MAQUEDA ABREU, M. L., "La violencia contra las mujeres. Una revisión crítica de la Ley Integral", en Revista Penal, 2006; p. 176 a 187, disponible en: <http://uhu.es/revistapenal/index.php/penal/article/ viewFile/289/280>. Acceso en: 05 jan. 2018.

ONUMUJERES. Hechos y cifras: Acabar con la violencia contra mujeres y niñas. 2016. Disponible en: $<$ http://www.unwomen.org/es/what-we-do/ending-violence-against-women/facts-and-figures>. Acceso en: 05 jan. 2018.

ONUMUJERES. Infografía: Violencia contra las mujeres. 2015. Disponible en: <http://www.unwomen. org/es/digital-library/multimedia/2015/11/infographic-violence-against-women>. Acceso en: 05 jan. 2018.

RAMÓN RIBAS, E., Los delitos de violencia de género según la jurisprudencia actual, en Estudios Penales y Criminológicos, no 33, 2013; p. 401 a 464. Disponible en: <http://www.usc.es/revistas/index.php/epc/ article/view/1323 >. Acceso en: 05 jan. 2018.

RUIZ-RICO RUÍZ, C. Aproximación a los nuevos retos jurídicos de la violencia de género: la responsabilidad pública, en Derecho y cambio social, 2014; p. 10; Disponible en: <https://dialnet.unirioja.es/descarga/ articulo/5472798.pdf>. Acceso en: 05 jan. 2018.

SORIANO, OLGA FUENTES. "La constitucionalidad de la Ley Orgánica de medidas de protección integral contra la violencia de género", La Ley: Revista jurídica española de doctrina, jurisprudencia y bibliografía, ISSN 0211-2744, no 5, 2005, p. 1153-1170.

UNICEF. Female Genital Mutilation/Cutting: A global concern. 2016. Disponible en: <http://www. unwomen.org/es/what-we-do/ending-violence-against-women/facts-and-figures\#notes>. Acceso en: 05 jan. 2018.

UNODC. Global Report on Trafficking in persons. Disponible en: <http://www.unodc.org/res/cld/ bibliography/global-report-on-trafficking-in-persons_html/GLOTIP_2014_full_report.pdf >. p. 5 y 11, 2014. Acceso en: 05 jan. 2018.

VALEIJE ALVÁVEZ, I., Penas accesorias, prohibiciones del art. 48.2 CP y delito de quebrantamiento de condena. Consideraciones críticas sobre al artículo 57.2 del CP, en Estudios Penales y Criminológicos, no 26, p. 321 a 354, 2006.

VÁZQUEZ CAMACHO, S. J., El caso 'Campo Algodonero' ante la Corte Interamericana de Derechos Humanos, en Anuario Mexicano de Derecho Internacional. Vol. XI, 2011; p. 515 y ss. Disponible en: $<$ https://revistas.juridicas.unam.mx/index.php/derecho-internacional/article/view/361/623>. Acceso en: 05 jan. 2018. 